\title{
Thermal Degradation of Polystyrene by Lewis Acids in Solution
}

Vishal Karmore, and Giridhar Madras

\author{
Ind. Eng. Chem. Res., 2002, 41 (4), 657-660 • DOI: 10.1021/ie0104262
}

Downloaded from http://pubs.acs.org on February 5, 2009

\section{More About This Article}

Additional resources and features associated with this article are available within the HTML version:

- $\quad$ Supporting Information

- Access to high resolution figures

- $\quad$ Links to articles and content related to this article

- $\quad$ Copyright permission to reproduce figures and/or text from this article

\section{View the Full Text HTML}




\title{
Thermal Degradation of Polystyrene by Lewis Acids in Solution
}

\author{
Vishal Karmore and Giridhar Madras* \\ Department of Chemical Enginering, Indian Institute of Science, Bangal ore, 560012 India
}

\begin{abstract}
The degradation of polystyrene in various Lewis acids [aluminum chloride, ferric chloride, boron triflouride etherate, and tin(IV) chloride] at different temperatures $\left(75-125^{\circ} \mathrm{C}\right)$ has been studied in this work. The evolution of the molecular weight distribution (MWD) has been model ed using continuous distribution kinetics with a stoichiometric kernel for random chain scission. The degradation rate was the highest in the presence of aluminum chloride. The reactions were also carried out at different aluminum chloride concentrations, and the degradation rate was proportional to the fourth power of the Lewis acid concentration. The activation energy of polystyrene degradation in the presence of aluminum chloride, determined from the temperature dependence of the degradation rate coefficient, was $7.7 \mathrm{kcal} / \mathrm{mol}$.
\end{abstract}

\section{Introduction}

The study of polymer degradation is important because of its applications in polymer recycling, durability, and characterization. A variety of plastic wasterecycling methods have been established, and new recycling approaches are being devel oped to avoid the dumping of polymers in landfills. Most of the investigations on the degradation of polymers, however, are by pyrolysis at very high temperatures. Because of inherent problems with high viscosity, ${ }^{1}$ commercialization of the process is lacking. Degradation of polymers in solution has been proposed to amend some of the problems encountered in pyrolysis. ${ }^{1,2}$ The thermal degradations of polystyrene (PS), ${ }^{3}$ poly(styrene-allyl alcohol), ${ }^{4}$ poly(methyl methacrylate), ${ }^{5}$ and poly(vinyl acetate) ${ }^{6}$ in solution have been investigated.

The catalytic degradation of polystyrene in the presence of activated charcoal has been studied. ${ }^{7}$ The degradation of polystyrene has also been investigated in silica-alumina, ${ }^{8} \mathrm{HY}$, and HZHM-5 catalysts. ${ }^{9}$ Gaseous products were obtained over the catalysts, but a pronounced deactivation of the catalysts occurred through the deposition of coke. All of the above reactions were carried out by pyrolysis at high temperatures. Polystyrene degradation was investigated in the presence of aluminum chloride at $50{ }^{\circ} \mathrm{C}$, and a linear decrease in molecular weight was observed. ${ }^{10}$ Pulanskzy and coworkers ${ }^{11}$ investigated the degradation of polystyrene in the presence of Lewis acids. However, all of the above studies were conducted on the polystyrene melt. To the best of our knowledge, no comprehensive study has been conducted on the degradation of polystyrene in solution in the presence of Lewis acids.

The objective of the present work is to study degradation of PS by Lewis acids in chlorobenzene at various temperatures and at various mass concentrations of Lewis acid. A continuous kinetics model for the degra-

* Author to whom correspondence should be addressed. Phone: 91-80-3092321. Fax: 91-80-3600683. E-mail: giridhar@ chemeng.iisc.ernet.in. dation of PS has been used that satisfactorily explains the experimental observations. The experimental observations can be explained by random chain scissions that are first-order in polymer concentration and fourthorder in Lewis acid concentration.

\section{Experiments}

Materials. Polystyrene $\left(M_{n}=200000\right.$, polydispersity $=1.4$ ) was used in the experiments. Chlorobenzene, aluminum chloride, ferric chloride anhydrous, stannous chloride [tin(IV) chloride], and boron trifluoride etherate (all from Aldrich Chemicals) were used in the degradation experiments.

Degradation Experiments. The degradation of polystyrene was carried out in a round-bottomed flask with continuous stirring at various temperatures $\left(75-125^{\circ} \mathrm{C}\right)$. The temperature was controlled to within $\pm 1{ }^{\circ} \mathrm{C}$ of the set point with an on-off controller (Thermotherm). The reactor was charged with $100 \mathrm{~mL}$ of chl orobenzene, and the temperature was raised to the reaction temperature. The required amount of Lewis acid ( $1-2.7 \mathrm{~g} / \mathrm{L})$ and $0.2 \mathrm{~g}$ of polystyrene were added to the reactor. Samples of $1 \mathrm{~mL}$ were taken at regular intervals for subsequent analysis. Control experiments were conducted without the acids, and no degradation of polystyrene was observed at the investigated temperatures. On the basis of triplicate experiments, the uncertainty in the rate coefficients was judged to be less than $5 \%$.

GPC Analysis. The samples were analyzed by GPC at $50{ }^{\circ} \mathrm{C}$ with THF (Merck) as the eluent at a flow rate of $1 \mathrm{~mL} / \mathrm{min}$. Three columns (HR4, HR3, HRO.5) (300 $\mathrm{mm} \times 7.5 \mathrm{~mm}$ ) packed with cross-linked polystyrenedivinyl benzene were used in series for efficient separation of molecular weight. The refractive index was continuously monitored with a differential refractometer (Waters R401) and converted to a MWD with a calibration curve based on polystyrene standards (Waters). ${ }^{12}$

\section{Theoretical Model}

Polymers can undergo chain scission to form lowermolecular-weight (MW) products. Chain scission can 
occur either at the chain end, yielding a specific product, or at a random position along the chain, yielding a range of lower-MW products. Continuous distribution kinetics considers the polymer to be a mixture of a large number of different-sized molecules with the MW $\mathrm{x}$ as a continuous variable

$$
\begin{gathered}
P(x)+C \stackrel{k_{1}}{\longrightarrow} P^{+}(x)+C \\
P^{+}(x) \stackrel{k_{2}}{\longrightarrow} P^{+}\left(x^{\prime}\right)+P\left(x-x^{\prime}\right)
\end{gathered}
$$

The catalytic degradation of polystyrene ${ }^{11}$ involves an initiation step in which the hydrogen atom attached to the benzyl carbon is abstracted as a hydride ion. The resulting polymeric carbocation undergoes $\beta$-scission, resulting in a decrease in the molecular weight. Reactions $A$ and $B$ represent ion formation resulting from attack of Lewis acid and binary fragmentation of the resulting polymeric carbocation, $\mathrm{P}^{+}\left(\mathrm{x}^{\prime}\right)$, at random points along the chain forming the ion. The governing population balance equation for reactions $A$ and $B$ in a batch reactor can be expressed as ${ }^{13}$

$$
\begin{aligned}
\partial p / \partial t=-k_{1}(x) p(x, t) & C^{4}+ \\
& 2 \int_{x}^{\infty} k_{2}\left(x^{\prime}\right) p^{+}\left(x^{\prime}, t\right) \Omega\left(x, x^{\prime}\right) d x^{\prime}
\end{aligned}
$$

$\partial \mathrm{p}^{+} / \partial \mathrm{t}=\mathrm{k}_{1}(\mathrm{x}) \mathrm{p}(\mathrm{x}, \mathrm{t}) \mathrm{C}^{4}+$

$$
2 \int_{x}^{\infty} k_{2}\left(x^{\prime}\right) p^{+}\left(x^{\prime}, t\right) \Omega\left(x, x^{\prime}\right) d x^{\prime}-k_{2} p^{+}(x, t)
$$

where the kernel $\Omega\left(\mathrm{x}, \mathrm{x}^{\prime}\right)$ determines the distribution of scission products and is given by $1 / x^{\prime}$ for random scission. The rate coefficients are assumed to depend linearly on the molecular weight, that is, $\mathrm{k}_{1}(\mathrm{x})=\mathrm{k}_{1} \mathrm{x}$ and $\mathrm{k}_{2}(\mathrm{x})=\mathrm{k}_{2} \mathrm{x}$. The moment operation, defined by $\mathrm{p}^{(\mathrm{n})}(\mathrm{t})=$ $\int_{0}^{\infty} x^{n} p(x, t) d x$, applied to eqs 1 and 2 yields

$$
\begin{gathered}
d p^{(n)} / d t=-k_{1} p^{(1+n)} C^{4}+k_{2}(n+1)^{-1}\left(p^{+}\right)^{(1+n)} \\
d p^{+(n)} / d t=k_{1} p^{(1+n)} C^{4}+k_{2}(n+1)^{-1}\left(p^{+}\right)^{(1+n)}- \\
k_{2}\left(p^{+}\right)^{(1+n)}
\end{gathered}
$$

The initial conditions for eqs 3 and 4 are $p^{(n)}(t=0)=p_{0}(n)$ and $p^{+(n)}(t=0)=0$. Assuming that the change in the carbocation concentration with time is negligible, $d\left(p^{+}\right)^{(n)} /$ $\mathrm{dt}=0$, one obtains

$$
\left(p^{+}\right)^{(n)}(x)=\frac{k_{1} p^{(1+n)} C^{4}}{k_{2}-k_{2} /(n+1)}
$$

Substituting this result into eq 3 yields

$$
d p^{(n)} / d t=(n-1)^{-1} k_{1} p^{(1+n)} C^{4}
$$

Equation 5 for the zeroth moment, $\mathrm{n}=0$, is $\mathrm{dp}^{(0)} / \mathrm{dt}=$ $-\mathrm{k}_{1} \mathrm{p}^{(1)} \mathrm{C}^{4}$, which can besolved with the initial conditions to obtain

$$
\mathrm{p}^{(0)}-\mathrm{p}_{0}{ }^{(0)}=\mathrm{k}_{1} \mathrm{p}^{(1)} \mathrm{C}^{4} \mathrm{t}
$$

The first moment, $\mathrm{n}=1$, from eq 5 is

$$
\mathrm{dp}^{(1)} / \mathrm{dt}=0
$$

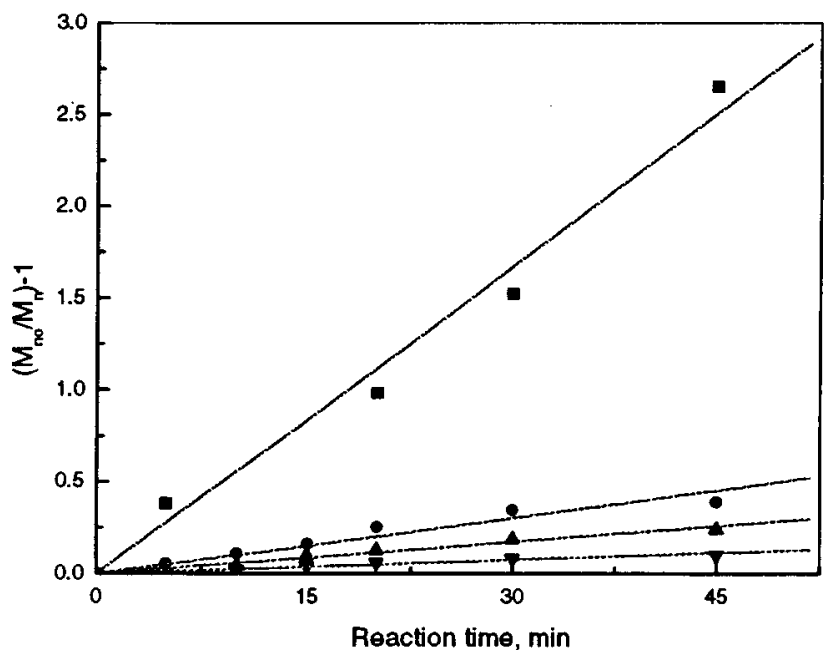

Figure 1. Plot of $\left(\mathrm{M}_{\mathrm{n}} / \mathrm{M}_{\mathrm{n}}\right)-1$ versus $\theta$ at $100{ }^{\circ} \mathrm{C}$ with different Lewis acids at $2 \mathrm{~g} / \mathrm{L}$ concentration: $\mathbf{\square}$, aluminum chloride; $\bullet$, ferric chloride; $\mathbf{\Delta}$, stannous chloride; $\boldsymbol{\nabla}$, boron trifluoride etherate.

Equation 7 indicates that $p^{(1)}$ is constant $\left(=p_{0}^{(1)}\right)$, i.e., the mass of the polymer is conserved. The ratio of the first moment to the zeroth moment gives the numberaverage molecular weight of the polymer, $M_{n}=p^{(1)} / p^{(0)}$. Thus, eq 6 can be rewritten as

$$
\left(M_{n 0} / M_{n}\right)-1=k_{1} M_{n 0} C^{4} t=k_{c} t=\theta
$$

\section{Results and Discussion}

The degradation of polystyrene in different Lewis acids was investigated at three different temperatures in the range $75-125^{\circ} \mathrm{C}$. Equation 8 depicts the variation of the number-average $\mathrm{MW}$ with reaction time and acid concentration. Figure 1 shows a pl ot of $\left(M_{n 0} / M_{n}\right)-$ 1 versus time for different Lewis acids [aluminum chloride, ferric chloride, boron triflouride etherate, and tin(IV) chloride], each at a concentration of $2 \mathrm{~g} / \mathrm{L}$ at 100 ${ }^{\circ} \mathrm{C}$. The slopes of the lines give the corresponding degradation rate coefficients. The degradation rate coefficients, $\mathrm{k}_{\mathrm{c}}$, are $9.28 \times 10^{-4} \mathrm{~s}^{-1}$ for $\mathrm{AlCl}_{3}, 1.67 \times 10^{-4}$ $\mathrm{s}^{-1}$ for $\mathrm{FeCl}_{3}, 9.5 \times 10^{-5} \mathrm{~s}^{-1}$ for $\mathrm{SnCl}_{4}$, and $4.16 \times 10^{-5}$ $\mathrm{s}^{-1}$ for boron triflouride etherate. Thus, the order of activity of the Lewis acids is $\mathrm{AlCl}_{3} \gg \mathrm{FeCl}_{3}>\mathrm{SnCl}_{4}>$ boron triflouride etherate. Among the chlorides, Al, Fe, and $\mathrm{Sn}$ have el ectronegativities of $1.61,1.83$, and 1.96, respectively, indicating that the degradation rate is dependent on the electronegativity of the Lewis acid. This phenomenon indicates that the catalytic degradation of polystyrene commences with an elimination of hydrogen atom from the benzyl carbon and that the Lewis acid, depending on its electronegativity, promotes the elimination of the hydrogen atom. Because the degradation rate of polystyrene was greatest in the presence of aluminum chloride, the effects of concentration and temperature on the degradation rate were studied for this Lewis acid.

Figure 2 depicts the variation of the number-average $M W$ with reaction time $t$ in the presence of aluminum chloride at a concentration of $1.5 \mathrm{~g} / \mathrm{L}(0.01125 \mathrm{~mol} / \mathrm{L})$ for different temperatures. The degradation rate coefficients, $\mathrm{k}_{\mathrm{c}}$, obtained from the slopes are $1.6 \times 10^{-4}, 3.35$ $\times 10^{-4}$, and $6.4 \times 10^{-4} \mathrm{~s}^{-1}$ at 75,100 , and $125^{\circ} \mathrm{C}$, respectively. These rate coefficients are substantially higher than the rate coefficients observed for polysty- 


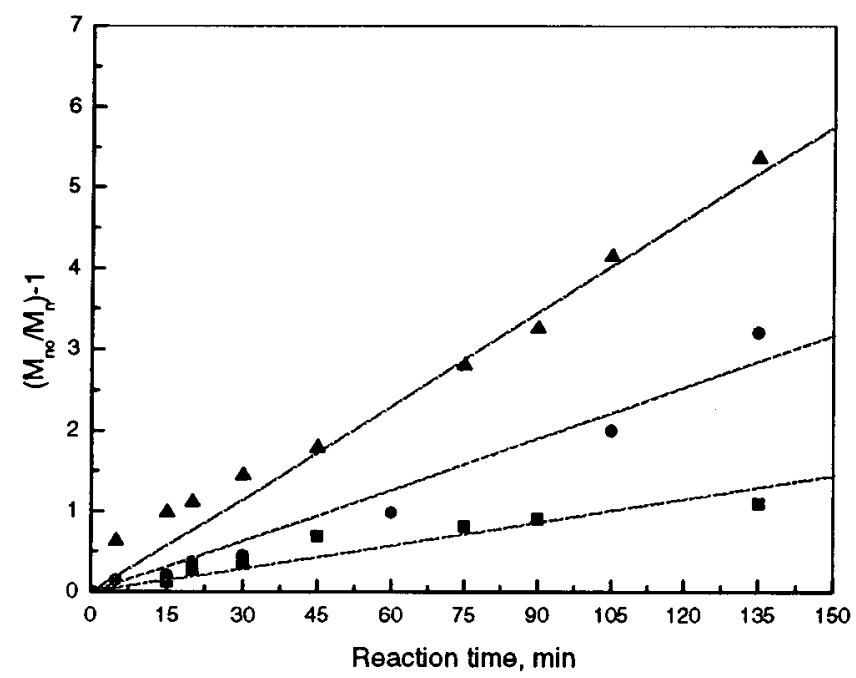

Figure 2. Plot of $\left(M_{n d} / M_{n}\right)-1$ versus $t$ in $1.5 \mathrm{~g} / \mathrm{L}$ of aluminum chloride at different temperatures: $\boldsymbol{\Lambda}, 125 ; \bullet, 100 ; \mathbf{\square}, 75^{\circ} \mathrm{C}$.

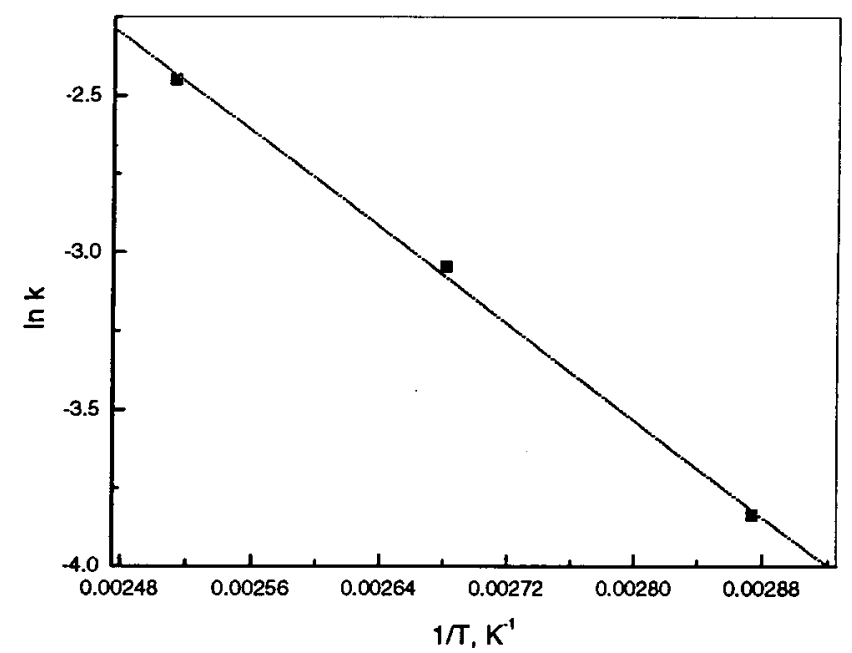

Figure 3. Arrhenius plot of the rate coefficient with temperature: $\mathbf{\square}$, data points; - linear fit.

rene in solution at $300{ }^{\circ} \mathrm{C}$ investigated by Chiantore $\left(1.33 \times 10^{-5} \mathrm{~s}^{-1}\right)^{14}$ and Madras $\left(7.5 \times 10^{-5} \mathrm{~s}^{-1}\right) .{ }^{15}$

Figure 3 shows the temperature dependence of the rate coefficients in an Arrhenius plot. The activation energy is obtained from the slope and corresponds to $7.7 \mathrm{kcal} / \mathrm{mol}$, which is comparable to the activation energies reported by other $\mathrm{s}^{14,15}$ for the solution degradation of polystyrene (between 200 and $300{ }^{\circ} \mathrm{C}$ ).

The time variation of $\left(M_{n o} / M_{n}\right)-1$ for different aluminum chloride concentrations between 1 and 2.7 $\mathrm{g} / \mathrm{L}$ at $100{ }^{\circ} \mathrm{C}$ was also investigated. The rate coefficients, $\mathrm{k}_{\mathrm{c}}\left(\times 10^{-4}\right)$, obtained were $0.53,1.17,3.18,4.95$, $9.28,23.8$, and $36.8 \mathrm{~s}^{-1}$ for aluminum chloride concentrations of $1.0,1.25,1.5,1.75,2.0,2.4$, and $2.7 \mathrm{~g} / \mathrm{L}$, respectively. As defined in eq $8, \theta=\mathrm{k}_{\mathrm{c}} \mathrm{t}$, and a plot of $\left(M_{n o} / M_{n}\right)-1$ versus $\theta$ should fall on a straight line independent of the aluminum chloride concentration. This is shown in Figure 4, wherein all of the data points fall on a single line (within experimental error). Equation 8 establishes that $\mathrm{k}_{\mathrm{c}}=\mathrm{k}_{1} \mathrm{M}_{n 0} \mathrm{C}^{4}$, indicating that a plot of $\mathrm{k}_{\mathrm{c}}$ vs $\mathrm{C}^{4}$ should be a straight line with a slope of $\mathrm{k}_{1} \mathrm{M}_{\mathrm{n} 0}$. The linear plot of the rate coefficient with the fourth power of the aluminum chloride mass concentration is shown as an inset in Figure 4. The degradation rate of polystyrene is proportional to the fourth order of the Lewis acid concentration, indicating that the

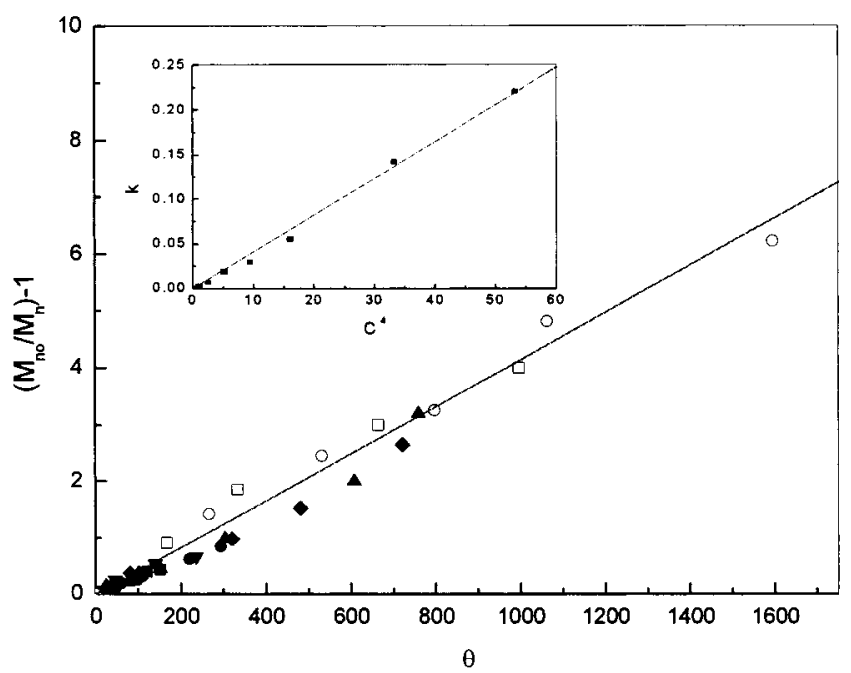

Figure 4. Plot of $\left(M_{n o} / M_{n}\right)-1$ versus $\theta$ at $100{ }^{\circ} \mathrm{C}$ for different concentrations of aluminum chloride: $\mathbf{\square}, 1 ; \boldsymbol{\bullet}, 1.25 ; \mathbf{\Lambda}, 1.5 ; \mathbf{\nabla}, 1.75$; $\checkmark, 2.0 ; \square, 2.4 ; \bigcirc, 2.7 \mathrm{~g} / \mathrm{L}$. The inset of the figure shows the variation of the degradation rate coefficent, $k_{c}$, with the fourth power of the mass concentration of aluminum chloride at $100{ }^{\circ} \mathrm{C}$.

mechanism underlying the degradation might be complex. Further studies on polystyrene degradation in the presence of other Lewis acids and the products of scission have to be examined before a mechanism can be proposed to explain the dependence of the degradation rate coefficient on the fourth order of the Lewis acid concentration.

\section{Conclusion}

The effect of various Lewis acids on the thermal degradation of polystyrene was investigated. An ionic mechanism of degradation was proposed, and the degradation rate coefficients were determined by using a continuous distribution kinetic model. The degradation rate was enhanced by several orders of magnitude in the presence of the acids. Among the investigated acids, aluminum chloride was found to promote the maximum degradation rate for polystyrene. The effects of temperature and concentration on the degradation rate were also investigated in the study. The activation energy for degradation was $7.7 \mathrm{kcal} / \mathrm{mol}$, and the degradation rate was proportional to the fourth power of the aluminum chloride mass concentration.

\section{Acknowledgment}

The authors thank the Department of Science and Technology, India, for financial support.

\section{Literature Cited}

(1) Murakata, T.; Saito, Y.; Yoshikawa, T.; Suzuki, T.; Sato, S. Solvent Effect on Thermal Degradation of Polystyrene and Poly$\alpha$-methylstyrene. Polymer 1993, 34, 1436.

(2) Murakata, T.; Saito, M.; Sato, H.; Hirai, T.; Sato, S. Selective Pyrolysis of Polystyrene to That with a Desired Low Polymeric Degree. J . Appl. Polym. Sci. 1998, 70, 2299.

(3) Sato, S.; Murakata, T.; Baba, S.; Saito, Y.; Watanabe, S. Solvent Effect of Polystyrene. J . Appl. Polym. Sci. 1990, 40, 2065.

(4) Madras, G.; Smith, J. M.; McCoy, B. J. Effect of Tetralin on the Degradation of Polymer in Solution. Ind. Eng. Chem. Res. 1995, 34, 4222.

(5) Madras, G.; Smith, J . M.; McCoy, B. J . Degradation of Poly(methyl methacrylate) in Solution. Ind. Eng. Chem. Res. 1996, 35, 1795. 
660 Ind. Eng. Chem. Res., Vol. 41, No. 4, 2002

(6) Chattopadyay, S.; Madras, G. Effect of Hydrogen Donor on the Degradation of Polyvinyl Acetate in Solution. J . Appl. Polym. Sci. 2001, 81, 1996.

(7) Ide, S.; Nanbu, H.; Kuroki, T.; Ikemura, T. Catalytic Degradation of Polystyrene in the Presence of Activated Charcoal J. Polym. Sci. Technol. 1984, 6, 69.

(8) Yamamoto, M.; Takamiya, N. Cracking of Polystyrene and Polyethylene on Silica Alumina. Bull. Sci. Eng. Res. Lab. 1985 $111,8$.

(9) Uemichi, Y.; Kamibayashi, H.; Ugioka, M.; Kanazuka, T. Degradation of polystyrene over solid acid catalysts. J pn. J . Polym. Sci. Technol. 1993, 50, 887.

(10) Nanbu, H.; Sakuma, Y.; I shihara, Y.; Takesue, T.; I kemura, T. Catalytic Degradation of Polystyrene in the Presence of Aluminum Chloride Catalyst. Polym. Degrad. Stab. 1987, 19, 61.

(11) Pulanskzy, B.; Kennedy, J . P.; Kelen, T.; Tudos, F. Cationic Reactions in the Melt. I. The Effect of Lewis Acids on Polystyrene. Polym. Bull. 1981, 5, 469.
(12) Karmore, V.; Madras, G. Degradation of Polystyrene in Supercritical Benzene. Ind. Eng. Chem. Res. 2000, 39, 4020.

(13) Wang, M.; Smith, J . M.; McCoy, B. J . Continuous Kinetics for Thermal Degradation of Polymer in Solution. AIChE J . 1995 41, 1521.

(14) Chiantore, O.; Camino, G.; Costa, L.; Grassie, N. Weak Links in Polystyrene. Polym. Degrad. Stab. 1981, 3, 209.

(15) Madras, G.; Smith, J. M.; McCoy, B. J. Degradation Kinetics of Polystyrene in Solution. Polym. Degrad. Stab. 1999, $58,131$.

Received for review May 11, 2001 Revised manuscript received October 12, 2001 Accepted November 20, 2001

IE 0104262 